\title{
MONOAXIAL PEDICLE SCREWS WITH SUBLAMINAR FIXATIONS IN THE CORRECTION OF ADOLESCENT IDIOPATHIC SCOLIOSIS
}

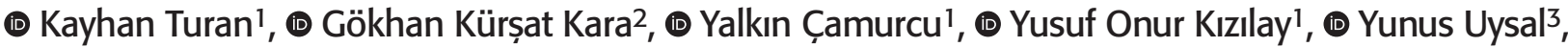 \\ (D) Ufuk Aydınlı4 \\ 1 Istanbul Atlas University Faculty of Medicine, Department of Orthopaedics and Traumatology, İstanbul, Turkey \\ 2Istinye University Faculty of Medicine, Department of Orthopaedics and Traumatology, Istanbul, Turkey \\ ${ }^{3}$ Private Hospital Arrhythmia Osmangazi, Department of Orthopaedics and Traumatology, Bursa, Turkey \\ ${ }^{4}$ Verom Spine Health and Tumor Center, Orthopedics and Traumatology Specialist, Spine and Tumor Surgery, Bursa, Turkey
}

Objective: To evaluate the radiological outcomes of posterior spinal instrumentation by using monoaxial pedicle screws with sublaminar fixations for the treatment adolescent idiopathic scoliosis (AIS).

Materials and Methods: The data of 14 patients who underwent posterior instrumentation by using monoaxial pedicle screws with sublaminar fixations for the treatment of AIS between 2010 and 2019 were retrospectively analyzed. Patients' age, gender, preoperative Risser classification, preoperative Lenke classification, and operative data were recorded through our medical records. Proximal thoracic (PT), main thoracic (MT), thoracolumbar/lumbar (TL/L) curve Cobb angles as well as thoracic kyphosis (TK) and lumbar lordosis (LL) Cobb angles were measured through preoperative and postoperative standing full spine X-rays.

Results: The mean preoperative PT curve Cobb angle was 33.7 degrees, and it was 4 degrees postoperatively $(p=0.068)$. The mean preoperative MT curve Cobb angle was 53.3 degrees and it was 8.7 degrees postoperatively $(p=0.008)$. The mean preoperative TL/L curve Cobb angle was 43 degrees and it was 9.2 degrees postoperatively $(p=0.005)$. The overall mean coronal plane correction ratio was $84 \%$. The mean preoperative TK Cobb angle was $25.2 \pm 17.8$ degrees and it was $32.9 \pm 8.9$ postoperatively $(p=0.101)$.

Conclusion: According to the results acquired from this study, monoaxial pedicle screws with sublaminar fixations demonstrated an efficient correction in both PT, MT, and TL/L curves and restoration of TK in AIS surgery.

Keywords: Adolescent idiopathic scoliosis, pedicle screw, monoaxial, sublaminar fixation, correction

\section{INTRODUCTION}

Posterior spinal instrumentation is the standard method for the surgical correction of adolescent idiopathic scoliosis (AIS) (1). From the first introduction of pedicle screws by Roy-Camille in 1979 pedicle screw design evolved over the years ${ }^{(2)}$. Recently, pedicle screw instrumentation has become the most commonly preferred method for the treatment of scoliosis ${ }^{(3)}$. However, there is still debate about the choice of fixation method regarding using either a hybrid system, which consists of laminar wires/ tapes, hooks, and pedicle screws, or using only mono/polyaxial pedicle screws ${ }^{(4)}$.

Monoaxial pedicle screws were the first introduced pedicle screw and reported as having the advantage of the better correction of vertebral rotation compared to polyaxial screws ${ }^{(3,4)}$. However, it can be difficult to achieve complete seating of the screw into the rod which may result in an inadequate connection between the rod and the screw and it can cause fixation failure $e^{(5)}$. A recent study also remarked the difficulty of surgical correction among junior surgeons and mentioned that senior surgeons used significantly more monoaxial screws and achieved better correction in the treatment of $\mathrm{AIS}^{(6)}$. In their study comparing monoaxial and polyaxial pedicle screw in the treatment of AIS, Kuklo et al. ${ }^{(3)}$ also reported greater correction of rotational and thoracic torsion deformities compared to polyaxial screws; however, the authors did not find any significant difference between monoaxial and polyaxial screws in terms of fixation stability and coronal plane deformity correction.

Address for Correspondence: Yalkın Çamurcu, İstanbul Atlas University Faculty of Medicine, Department of Orthopaedics and Traumatology, İstanbul, Turkey Phone: +90 5334802310 E-mail: yalkin.camurcu@gmail.com Received: 27.01.2021 Accepted: 24.03.2021

ORCID ID: orcid.org/0000-0002-3900-5162 
In the literature, many studies exist reporting the outcomes of monoaxial screws in the treatment of thoracolumbar burst fractures. There are also studies comparing the biomechanical properties of monoaxial and polyaxial pedicle screws. Previously, Kuklo et al. ${ }^{(3)}$ and Lonner et al. ${ }^{(4)}$ compared monoaxial and polyaxial thoracic pedicle screws in the treatment of thoracic scoliosis. However, to date, we could not find any study evaluating the outcomes of monoaxial pedicle screw fixation with sublaminar fixation in the correction of AIS. In the current study, we aimed to evaluate the radiological outcomes of posterior spinal instrumentation by using monoaxial pedicle screws with sublaminar fixations for the surgical treatment of AIS.

\section{MATERIALS AND METHODS}

We hypothesized that monoaxial pedicle screws with sublaminar fixations resulted in an efficient coronal plane deformity correction and restoration of hypokyphosis compared to the reported studies in the literature.

\section{Study Population}

This retrospective study was performed in accordance with the "Declaration of Helsinki". Ethics committee approval was received from İstanbul Atlas University Non-Interventional Scientific Research Ethics Committee (25.06.2021-4758). Informed consent was obtained for each patient. We retrospectively reviewed the prospectively collected clinical and radiological data of 14 consecutive patients who underwent posterior spinal instrumentation for the treatment of AIS between 2010 and 2019. Patients who underwent surgical correction of AIS by using monoaxial pedicle screw and sublaminar tape fixation with a minimum follow-up of 1 year were included in the study. There was no patient with incomplete follow-up and medical records. Fourteen patients (11 females, 3 males) with the mean age of $14.2 \pm 2.2$ years (ranges, 12 to 18 years) participated in the study. The mean follow-up time was 17 months (ranges, 12 to 36 months).

\section{Operative Technique}

All surgeries were performed by the senior author of this study (UA) on a radiolucent table in the prone position. A standard midline approach was used for the posterior spinal instrumentation. Monoaxial pedicle screws were placed either unilaterally or bilaterally according to the fusion levels detected preoperatively. The deformity was corrected by connecting screw and pre-contoured rods gradually by clamps. Depended to the thoracic deformity, 3 or 4 sublaminar fixations were performed in all patients from the convex side of the deformity. A combination of autologous spinous processes autograft and cortico-spongious bone allografts were used for grafting. All patients received prophylactic first-generation cephalosporin 30 minutes prior to the procedure. Postoperative intravenous antibiotics were continued for 24 hours. No postoperative bracing was used in any patients and all patients were mobilized at postoperative $1^{\text {st }}$ day.

\section{Data Evaluation}

Patients' age, gender, preoperative Risser classification, preoperative Lenke classification, and instrumentation levels were recorded through our medical records. Patients preoperative and postoperative full spine posterior-anterior and lateral radiographs were assessed by the senior author (UA) (Figure 1 and 2). Coronal Cobb angles were measured for the proximal thoracic (PT), main thoracic (MT), thoracolumbar/ lumbar (TL/L) curves. Sagittal Cobb angles were measured for thoracic kyphosis (TK) and lumbar lordosis (LL). The instrumentation ratio which defined the ratio of screw fixation at the fusion levels was calculated. Bilateral monoaxial screw fixation at all levels was considered as a $100 \%$ instrumentation. The correction ratio was also calculated according to the preoperative and postoperative Cobb angles.

\section{Statistical Analysis}

Statistical analysis was performed by using SPSS 25.0 (SPSS Inc., IBM, NY, USA). Continuous data were given as means and standard deviations, whereas categorical data were given as frequencies and percentages. Comparison of preoperative
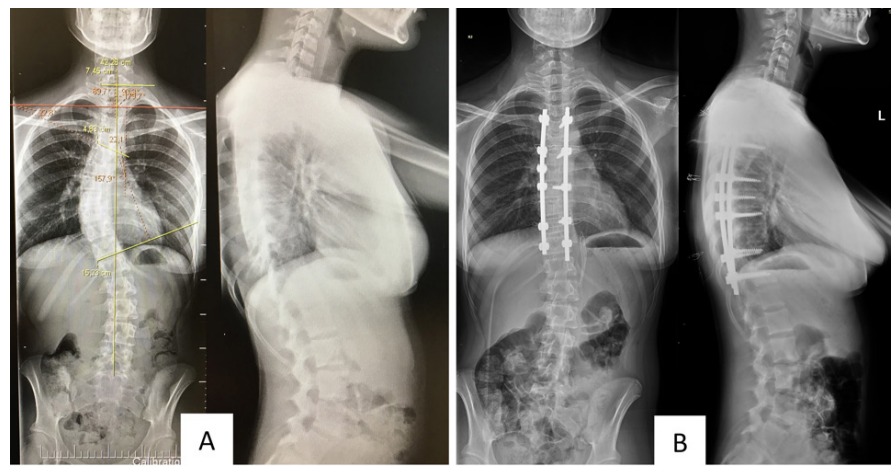

Figure 1. A) Preoperative standing posterior-anterior and lateral radiographs of a Lenke $1 \mathrm{~B}$ patient (Patient 10) with 45 degrees MT, 40 degrees TL, and 25 degrees TK Cobb angles. B) The patient underwent posterior instrumentation between T4 and T11 levels, an $85 \%$ correction rate was achieved in the MT curve and a $63 \%$ correction rate was achieved in the TL curve
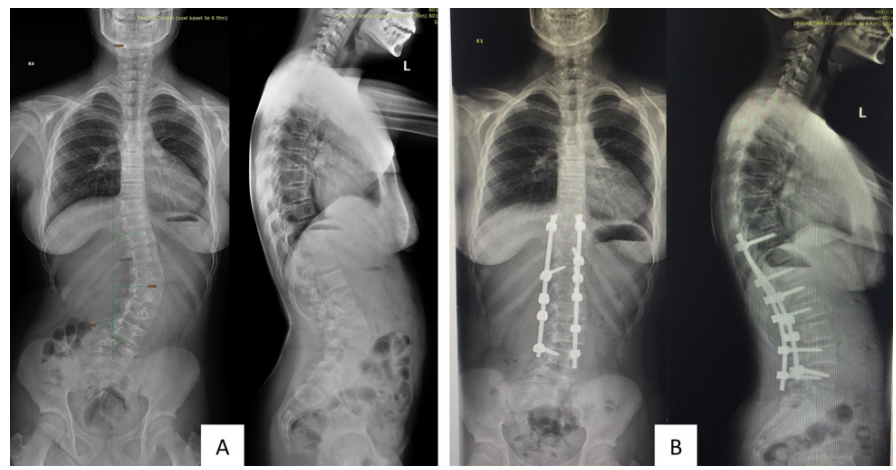

Figure 2. A) Preoperative standing posterior-anterior and lateral radiographs of a Lenke $5 \mathrm{C}$ patient (Patient 8) with $43 \mathrm{TL}$, and 46 degrees TK Cobb angles. B) The patient underwent posterior instrumentation between T9 and L4 levels, a 91\% correction rate was achieved in the TL curve 
and postoperative mean Cobb angles was performed by the Wilcoxon test. P-values lower than 0.05 were considered as statistically significant.

\section{RESULTS}

The preoperative clinical data of the patients were demonstrated in Table 1. The mean preoperative PT curve Cobb angle was $33.7 \pm 2.5$ degrees, and it was $4 \pm 5.3$ degrees postoperatively $(p=0.068)$. The mean preoperative MT curve Cobb angle was $53.3 \pm 7.5$ degrees and it was $8.7 \pm 4.4$ degrees postoperatively $(p=0.008)$. The mean preoperative TL/L curve Cobb angle was $43 \pm 9.8$ degrees and it was $9.2 \pm 7.7$ degrees postoperatively $(p=0.005)$.

The postoperative data were summarized in Table 2. The mean preoperative TK Cobb angle was $25.2 \pm 17.8$ degrees and it was $32.9 \pm 8.9$ postoperatively $(\mathrm{p}=0.101)$. The mean $\mathrm{LL}$ angle was $47.9 \pm 13.9$ degrees and it was $46.8 \pm 10.5$ postoperatively $(p=0.850)$.

The overall mean curve correction ratio was $84 \% \pm 14 \%$ and the mean monoaxial screw instrumentation ratio through all fusion levels was $72 \% \pm 10 \%$. No complication occurred during the follow-up time.

\section{DISCUSSION}

The most important finding of this was that we achieved a mean $88 \%$ correction ratio in the PT curve, a mean $84 \%$ correction ratio in the MT curve, and a mean $79 \%$ correction ration in the TL/L curve. Our correction ratio can easily be accepted as a higher ratio in comparison to the reported studies in the literature about the treatment of AIS by monoaxial screws ${ }^{(3,4,7)}$.
In their study comparing monoaxial and polyaxial screws in the treatment of Lenke type 1 AIS, Kuklo et al.(3) achieved a mean 41\% PT correction, $65 \%$ MT correction, and 55\% TL/L correction with monoaxial screws. Lonner et al.(4) reported a better MT correction by monoaxial screws (69\%) in their study comparing monoaxial, polyaxial, and hybrid constructs. Blondel et al. ${ }^{(7)}$ mentioned that the decrease in the thoracic Cobb angle was $72 \%$ in their monoaxial screw hybrid group.

Our results also demonstrated an increase in thoracic hypokyphosis and restoration of TK. We detected a relative hypokyphosis in our patients preoperatively (25.2 degrees) and it was corrected to normal values postoperatively (32.9 degrees). Kuklo et al. ${ }^{(3)}$ reported a mean 28.2 TK preoperatively and it was decreased to the mean 24.5 degrees postoperatively in their monoaxial screw fixation group. In their monoaxial screw group, Lonner et al. ${ }^{(4)}$ reported a preoperative mean 32 degrees TK and it was decreased to the mean 30 degrees postoperatively. Blondel et al.(7) achieved a better TK restoration in their hybrid polyaxial screw group compared to their hybrid monoaxial screw group. Acaroglu et al. ${ }^{(8)}$ also remarked the difficulty of 3D deformity in AIS correction surgery and mentioned that TK is decreased as the lengthening of the spinal column while correcting the coronal plane deformity. The authors reported an overall 0.5 -degree increase in thoracic hypokyphosis, in their study evaluating 53 articles about the treatment of AIS by various instruments. In our study, we achieved a mean 7.5 degrees correction in thoracic hypokyphosis. This finding can be explained by the augmentation of monoaxial screw fixation with sublaminar fixation. Acaroglu et al. ${ }^{(8)}$ also mentioned that increase in TK angle was highest in hybrid constructs. We also achieved a better increase in the TK angle by our monoaxial

Table 1. Preoperative data of the patients

\begin{tabular}{|c|c|c|c|c|c|c|c|c|c|}
\hline Patient & Age & Gender & $\begin{array}{l}\text { Risser } \\
\text { grade }\end{array}$ & $\begin{array}{l}\text { Lenke curve } \\
\text { type }\end{array}$ & $\begin{array}{l}\text { Preop } \\
\text { PT curve }\end{array}$ & $\begin{array}{l}\text { Preop MT } \\
\text { curve }\end{array}$ & $\begin{array}{l}\text { Preop TL/L } \\
\text { curve }\end{array}$ & $\begin{array}{l}\text { Preop } \\
\text { thoracic } \\
\text { kyphosis }\end{array}$ & $\begin{array}{l}\text { Preop lumbar } \\
\text { lordosis }\end{array}$ \\
\hline 1 & 15 & Female & 4 & $5 C$ & * & $*$ & 46 & 23 & 44 \\
\hline 2 & 16 & Female & 4 & $5 C$ & * & * & 42 & 53 & 64 \\
\hline 3 & 16 & Male & 4 & $2 \mathrm{~A}$ & 33 & 56 & 35 & 27 & 38 \\
\hline 4 & 14 & Female & 4 & $1 \mathrm{~B}$ & 36 & 48 & * & 32 & 52 \\
\hline 6 & 16 & Female & 5 & $5 C$ & * & $*$ & 41 & 5 & 24 \\
\hline 7 & 12 & Female & 3 & $1 \mathrm{~B}$ & * & 46 & 32 & 11 & 36 \\
\hline 8 & 12 & Female & 0 & $5 C$ & * & $*$ & 43 & 46 & 60 \\
\hline 9 & 18 & Male & 5 & $2 \mathrm{~A}$ & 36 & 49 & * & 32 & 48 \\
\hline 13 & 13 & Female & 4 & $1 \mathrm{~B}$ & * & 53 & * & 6 & 32 \\
\hline 14 & 18 & Male & 5 & $1 \mathrm{~B}$ & * & 60 & 38 & -6 & 34 \\
\hline
\end{tabular}


Table 2. Postoperative data of the patients.

\begin{tabular}{|c|c|c|c|c|c|c|c|c|c|c|}
\hline Patient & $\begin{array}{l}\text { Fusion } \\
\text { levels }\end{array}$ & $\begin{array}{l}\text { Instrument } \\
\text { ratio*** }\end{array}$ & $\begin{array}{l}\text { Neutral } \\
\text { vertebrae }\end{array}$ & $\begin{array}{l}\text { Stable } \\
\text { vertebrae }\end{array}$ & $\begin{array}{l}\text { Postop } \\
\text { PT curve }\end{array}$ & $\begin{array}{l}\text { Postop } \\
\text { MT } \\
\text { curve }\end{array}$ & $\begin{array}{l}\text { Postop } \\
\text { TL/L } \\
\text { curve }\end{array}$ & $\begin{array}{l}\text { Postop } \\
\text { thoracic } \\
\text { kyphosis }\end{array}$ & $\begin{array}{l}\text { Postop } \\
\text { lumbar } \\
\text { lordosis }\end{array}$ & $\begin{array}{l}\text { Correction } \\
\text { ratio**** }\end{array}$ \\
\hline 1 & T8-L4 & $77 \%$ & L5 & L4 & * & ${ }^{*}$ & 24 & 49 & 66 & $48 \%$ \\
\hline 2 & T10-L4 & $71 \%$ & L5 & L5 & * & * & 2 & 28 & 48 & $95 \%$ \\
\hline 3 & T2-L1 & $58 \%$ & L1 & L1 & 0 & 3 & 0 & 30 & 20 & $95 \%$ \\
\hline 4 & $\mathrm{~T} 2-\mathrm{T} 11$ & $70 \%$ & $\mathrm{~T} 11$ & T10 & 0 & 3 & * & 24 & 46 & $94 \%$ \\
\hline 5 & T11-L3 & $91 \%$ & L5 & L4 & * & * & 11 & 35 & 44 & $75 \%$ \\
\hline 6 & T6-L4 & $77 \%$ & L4 & L4 & * & * & 6 & 42 & 42 & $85 \%$ \\
\hline 7 & T2-T11 & $65 \%$ & T10-L5 & T11-L4 & * & 11 & 12 & 27 & 43 & $76-62 \%$ \\
\hline 8 & T9-L4 & $68 \%$ & L5 & L5 & * & ${ }^{*}$ & 4 & 40 & 56 & $91 \%$ \\
\hline 9 & T2-L1 & $62 \%$ & L1 & L1 & 13 & 15 & ${ }^{*}$ & 32 & 44 & $64-69 \%$ \\
\hline 10 & T4-T11 & $68 \%$ & T11-L4 & T11-L4 & ${ }^{*}$ & 7 & 15 & 26 & 54 & $85-63 \%$ \\
\hline 11 & T4-L2 & $63 \%$ & L3 & L3 & $*$ & 12 & $*$ & 30 & 38 & $77 \%$ \\
\hline 12 & T2-L4 & $66 \%$ & L5 & L5 & 3 & 10 & 0 & 50 & 60 & $90-86 \%$ \\
\hline 13 & T5-T12 & $87 \%$ & $\mathrm{~T} 12$ & L1 & $*$ & 4 & $*$ & 18 & 49 & $92 \%$ \\
\hline 14 & T4-T11 & $87 \%$ & T11-L4 & T11-L3 & * & 14 & 18 & 30 & 45 & $77-52 \%$ \\
\hline
\end{tabular}

screw and sublaminar fixation constructs. This issue should be investigated by further studies.

The choice of proper implant is still on debate. Some authors favor the use of hybrid constructs, which consists of hooks and wires, in thoracic curves in addition to pedicle screws; whereas, some authors recommended the use of all pedicle screw constructs(9-12). Aubin et al.(13) evaluated the implant selection of spine surgeons in the treatment of AIS through a spine surgery simulator, and they remarked the large variability between six surgeons in terms of implant selection, implant numbers, fusion levels, and rod rotation maneuvers. The authors concluded that this variability may be dependent on the surgeon's experiences ${ }^{(13)}$. This difference also exists between senior and junior spine surgeons. Qiao et al.(6) remarked that senior surgeons used more monoaxial screws and achieved better thoracic correction compared to junior counterparts in the treatment of AIS. With monoaxial screws, it can be difficult to achieve a perpendicular axis between the screw and rod, which may cause a gap between the rod and screw interference during tightening by a nut ${ }^{(14)}$. This situation can be challenging for the surgeons and provoke them to use polyaxial screws due to the freedom of the screw head in all axis. Wang et al.(15) also mentioned that extra forces to ensure proper rod setting is more needed with screws that have less freedom. Many biomechanical studies compared different designs of pedicle screws to evaluate the stability of fixation as well as the efficacy of correction. Liu et al.(14) performed a biomechanical investigation of direct vertebral derotation comparing monoaxial, uniplanar, and polyaxial pedicle screws. The authors achieved superior direct vertebral derotation by monoaxial screws compared to polyaxial and uniplanar screws ${ }^{(14)}$. In another study, Schroerlucke et al. ${ }^{(16)}$ showed that monoaxial and uniplanar screws resisted higher loads than polyaxial screws. Authors reported that polyaxial screws failed mostly by screw-head slippage while monoaxial and uniplanar screws mostly failed by breakage from screw or rod ${ }^{(16)}$. On the other hand, some authors recommended the use of polyaxial screws at the distal ends of long spinal fusion constructs in order to increase screw-rod interface strength ${ }^{(17,18)}$.

Low-density versus high-density instrumentation in the correction of AIS is another controversial issue in the literature. Some surgeons prefer to use fewer pedicle screws in order to decrease cost and implant-related complications while other surgeons favor using more pedicle screws to achieve a stronger construct ${ }^{(19)}$. A pedicle density ratio of $100 \%$ means that the pedicle screw is used bilaterally in all levels of fusion. In their study that evaluated high versus low pedicle screw density in Lenke 5 AIS, Sariyilmaz et al. ${ }^{(19)}$ mentioned that high pedicle screw density (96.6\%) and low pedicle screw density (75.4\%) did not significantly differ in terms of curve correction in early postoperative and mean 40 months follow-up. de Kleuver et al.(20) reported that $<80 \%$ pedicle screw density can be recommended in deformities up to 70 degrees according to a survey gathered from experienced spine surgeons. Our mean pedicle screw density was $72 \%$ which can be considered as low-density, and we achieved a mean $84 \%$ correction despite 
low-density. The relationship between low-density pedicle screws and types of screws should also be investigated by further studies.

\section{Study Limitations}

The main limitation of this study is its retrospective design. However, we evaluated a prospectively collected patient population. Besides, the retrospective design of the study prevented potential patient selection bias. The other important limitation of our study is its small and heterogeneous patient population. Nevertheless, our cohort is relatively similar to previous studies in the literature comparing the radiographic outcomes of different constructs in the treatment of AIS. The main strength of our study is being the first study in the literature individually evaluating the radiographic outcomes of posterior instrumentation by using only monoaxial pedicle screws in the treatment of AIS performed by the same surgeon.

\section{CONCLUSION}

According to the results acquired from this study, monoaxial pedicle screws with sublaminar fixations demonstrated an efficient correction in both PT, MT, and TL/L curves and restoration of TK in AIS surgery.

\section{Ethics}

Ethics Committee Approval: Ethics committee approval was received from İstanbul Atlas University Non-Interventional Scientific Research Ethics Committee (25.06.2021-4758).

Informed Consent: Informed consent was obtained from each participant.

Peer-review: Internally peer-reviewed.

\section{Authorship Contributions}

Concept: K.T., U.A., Design: K.T., U.A., Data Collection or Processing: G.K.K., Y.O.K., Y.U., Analysis or Interpretation: G.K.K., Y.O.K., Literature Search: Y.Ç., Y.U., Writing: K.T., Y.Ç.

Financial Disclosure: The authors declared that this study received no financial support.

Conflict of Interest: The authors have no conflicts of interest to declare.

\section{REFERENCES}

1. Bayraktar MK, Uğraş AA, Akyıldız MF, Görgeç M. Posterior Instrumentation And Spinal Fusion Results In Surgical Treatment Of Adolescent Idiopathic Scoliosis. J Turk Spinal Surg. 2019;30:5-12.

2. Malhotra D, Kalb S, Rodriguez-Martinez N, Hem DD, Perez-Orribo L, Crawford NR, Sonntag VK. Instrumentation of the posterior thoracolumbar spine: from wires to pedicle screws. Neurosurgery. 2014;10(Suppl 4):497-504; discussion 505.

3. Kuklo TR, Potter BK, Polly DW Jr, Lenke LG. Monaxial versus multiaxial thoracic pedicle screws in the correction of adolescent idiopathic scoliosis. Spine (Phila Pa 1976). 2005;30:2113-20.
4. Lonner BS, Auerbach JD, Boachie-Adjei O, Shah SA, Hosogane N, Newton PO. Treatment of thoracic scoliosis: are monoaxial thoracic pedicle screws the best form of fixation for correction?. Spine (Phila Pa 1976). 2009;34:845-51.

5. Wang X, Aubin CE, Crandall D, Parent S, Labelle H. Biomechanical analysis of 4 types of pedicle screws for scoliotic spine instrumentation. Spine (Phila Pa 1976). 2012;37:E823-E835.

6. Qiao J, Xiao L, Xu L, Shi B, Qian B, Zhu Z, et al. Comparison of Complications and Surgical Outcomes of Adolescent Idiopathic Scoliosis Between Junior Attending Surgeons and Senior Attending Surgeons. World Neurosurg. 2018; 115:e580-e584.

7. Blondel B, Lafage V, Farcy JP, Schwab F, Bollini G, Jouve JL. Influence of screw type on initial coronal and sagittal radiological correction with hybrid constructs in adolescent idiopathic scoliosis. Correction priorities. Orthop Traumatol Surg Res. 2012;98:873-8.

8. Acaroglu E, Doany M, Cetin E, Castelein R. Correction of rotational deformity and restoration of thoracic kyphosis are inversely related in posterior surgery for adolescent idiopathic scoliosis. Med Hypotheses. 2019;133:109396.

9. Liljenqvist UR, Halm HF, Link TM. Pedicle screw instrumentation of the thoracic spine in idiopathic scoliosis. Spine (Phila Pa 1976) 1997;22:2239-45.

10. Barr SJ, Schuette AM, Emans JB. Lumbar pedicle screws versus hooks. Results in double major curves in adolescent idiopathic scoliosis. Spine (Phila Pa 1976). 1997;22:1369-79.

11. Liljenqvist $U$, Lepsien $U$, Hackenberg L, Niemeyer $T$, Halm $H$ Comparative analysis of pedicle screw and hook instrumentation in posterior correction and fusion of idiopathic thoracic coliosis. Eur Spine J. 2002;11:336-43.

12. Suk SI, Kim WJ, Lee CS, Lee SM, Kim JH, Chung ER, et al. Indications of proximal thoracic curve fusion in thoracic adolescent idiopathic scoliosis: recognition and treatment of double thoracic curve pattern in adolescent idiopathic scoliosis treated with segmental instrumentation. Spine. 2000;25:2342-49.

13. Aubin $\mathrm{CE}$, Labelle $\mathrm{H}$, Ciolofan OC. Variability of spinal instrumentation configurations in adolescent idiopathic scoliosis. Eur Spine J. 2007; 16:57-64.

14. Liu PY, Lai PL, Lin CL. A biomechanical investigation of the retentive force of pedicle screw structures for different screw tulip designs. Clin Biomech (Bristol, Avon). 2019;70:23-30.

15. Wang X, Aubin CE, Labelle H, Parent S, Crandall D. Biomechanical analysis of corrective forces in spinal instrumentation for scoliosis treatment. Spine (Phila Pa 1976). 2012;37:E1479-E1487.

16. Schroerlucke SR, Steklov N, Mundis GM Jr, Marino JF, Akbarnia BA, Eastlack RK. How does a novel monoplanar pedicle screw perform biomechanically relative to monoaxial and polyaxial designs?. Clin Orthop Relat Res. 2014;472:2826-32.

17. Serhan H, Hammerberg K, O'Neil M, Sturm P, Mardjetko S, Crawford A. Intraoperative techniques to reduce the potential of set-screw loosening in long spinal constructs: a static and fatigue biomechanical investigation. J Spinal Disord Tech. 2010;23:e31-e36.

18. Voleti PB, Shen FH, Arlet V. Failure of Monoaxial Pedicle Screws at the Distal End of Scoliosis Constructs: A Case Series. Spine Deform. 2014;2:110-21.

19. Sariyilmaz K, Ozkunt O, Karademir G, Gemalmaz HC, Dikici F, Domanic $U$. Does pedicle screw density matter in Lenke type 5 adolescent idiopathic scoliosis? Medicine (Baltimore). 2018;97:e9581.

20. de Kleuver M, Lewis SJ, Germscheid NM, Kamper SJ, Alanay A, Bergen $\mathrm{SH}$, et al. Optimal surgical care for adolescent idiopathic scoliosis: an international consensus. Eur Spine J. 2014;23:2603-18. 